\title{
Erratum to: A correlation between the optical and mechanical properties of novel polysilane/ polysiloxane nanocomposites
}

\section{Sungho Lee}

\section{Erratum to: Polym. Bull. \\ DOI 10.1007/s00289-009-0093-4}

The manuscript "A correlation between the optical and mechanical properties of novel polysilane/polysiloxane nanocomposites by Sungho Lee that appeared earlier this year (Polym. Bull. (2009) 63:385-396; DOI 10.1007/s00289-009-0093-4)" has been retracted as the whole article was derived from the author's master thesis without getting the consent of the author's supervisor nor the acknowledgement of the supervisor's authorship.

The online version of the original article can be found under doi:10.1007/s00289-009-0093-4.

\section{S. Lee $(\bowtie)$}

LS Cable Ltd, Advanced R\&D Center, Polymer Technology Group, 555 Hogye-dong,

Dongan-gu, Anyang-si, Gyeonggi-do 431-080, Korea

e-mail: sunghol@1scable.com; kevin0610@hanmail.net 